\title{
Hepatitis B Virus Reactivation in Gastrointestinal Stromal Tumor Patients Treated With Imatinib
}

\author{
Tianxiang Lei ${ }^{1 \dagger}$, Fengbo Tan $^{1 \dagger}$, Zhouhua Hou ${ }^{2}$, Peng Liu ${ }^{1}$, Xianhui Zhao ${ }^{1}$ and Heli Liu ${ }^{1 *}$ \\ ${ }^{1}$ Department of Gastrointestinal Surgery, Xiangya Hospital, Central South University, Changsha, China, ${ }^{2}$ Department of \\ Infectious Diseases, Xiangya Hospital, Central South University, Changsha, China
}

OPEN ACCESS

Edited by:

Domenico M. D'Ugo,

Catholic University of the Sacred

Heart, Italy

Reviewed by:

Manidhar Reddy Lekkala,

University of Rochester, United States

$\mathrm{HaO} X u$,

Nanjing Medical University, China

${ }^{*}$ Correspondence:

Heli Liu

heliliu@csu.edu.cn

${ }^{\text {t}}$ These authors have contributed equally to this work

Specialty section: This article was submitted to Gastrointestinal Cancers, a section of the journal

Frontiers in Oncology

Received: 19 August 2020 Accepted: 07 December 2020

Published: 22 January 2021

Citation:

Lei T, Tan F, Hou Z, Liu P.

Zhao $X$ and Liu $H$ (2021)

Hepatitis $B$ Virus Reactivation in Gastrointestinal Stromal Tumor

Patients Treated With Imatinib.

Front. Oncol. 10:596500.

doi: 10.3389/fonc.2020.596500
Purpose: Hepatitis B virus reactivation $(\mathrm{HBVr})$ in patients with gastrointestinal stromal tumors (GISTs) have not been sufficiently characterized. This study aimed to review the possible mechanism of HBVr induced by imatinib and explore appropriate measures for patient management and monitoring.

Methods: The clinical data of GIST patients who experienced HBVr due to treatment with imatinib at Xiangya Hospital (Changsha, Hunan, China) were retrospectively analyzed. A literature review was also conducted.

Results: Five cases were analyzed, including 3 cases in this study. The average age of the patients was $61.8 \mathrm{y}$, with male preponderance (4 of $5 \mathrm{vs}$. 1 of 5). These patients received imatinib as adjuvant treatment $(n=4)$ or as neoadjuvant treatment $(n=1)$. Primary tumors were mostly located in the stomach $(n=4)$ or rectum $(n=1)$. High $(n=3)$ or intermediate $(n=1)$ recurrence risk was categorized using the postoperative pathological results $(n=4)$. Imatinib was then started at $400(n=4)$ or 200 mg $(n=1)$ daily. Patients first reported abnormal liver function during the $2^{\text {th }}(n=1), 6^{\text {th }}(n=3)$, or $10^{\text {th }}(n=1)$ month of treatment with imatinib. Some patients $(n=4)$ discontinued imatinib following HBVr; notably, 1 month after discontinuation, 1 patient experienced HBVr. Antivirals (entecavir $n=4$, tenofovir $n=1$ ), artificial extracorporeal liver support $(n=1)$, and liver transplant $(n=1)$ were effective approaches to treating HBVr. Most patients $(n=3)$ showed favorable progress, 1 patient underwent treatment, and 1 patient died due to severe liver failure induced by $\mathrm{HBV}$.

Conclusions: Although HBVr is a rare complication (6.12\%), HBV screening should be conducted before starting treatment with imatinib in GIST patients. Prophylactic therapy for hepatitis B surface antigen positive patients, prompt antiviral treatment and cessation of imatinib are also necessary.

Keywords: hepatitis B virus, reactivation, gastrointestinal stromal tumors, imatinib, mechanism 


\section{INTRODUCTION}

Gastrointestinal stromal tumors (GISTs) are the most common mesenchymal neoplasms located in the digestive tract, with an estimated annual incidence of 1-2 per 100,000 globally $(1,2)$. Most cases of GIST have activated mutations in KIT and plateletderived growth receptor alpha (PDGFRA). Since 2000, imatinib has been found to target KIT changes in GIST cells (3). More than $80 \%$ of GIST patients have benefited from treatment with imatinib (4). This therapy has become one of the standard treatments for GIST (5).

Hepatitis B virus reactivation ( $\mathrm{HBVr}$ ) is a common complication in tumor patients with chronic HBV infection and simultaneously undergoing cytotoxic chemotherapy or immunosuppressive therapy (6). HBV is a major global health problem chronically affecting more than 257 million people worldwide (7). However, HBVr in tumor patients may lead to liver function injury or fatal liver failure. This occurrence can interrupt therapy, delaying the effective treatment of tumor patients and consequently affecting prognosis.

However, the risk for HBVr during the treatment of GISTs by using imatinib is poorly understood. To the best of our knowledge, only 2 cases have been reported worldwide $(8,9)$. Thus, it is urgent to clarify the mechanism and summarize such cases in order to draw attention from the medical community and provide clinical guidance for patient management.

\section{METHODS AND MATERIALS}

We retrospectively reviewed the data of 869 patients with GIST from January 2007 to June 2020 through the hospital information system of Xiangya Hospital of Central South University (Changsha, Hunan, China). A total of 440 patients received imatinib as adjuvant treatment $(\mathrm{n}=428)$ or neoadjuvant treatment $(n=12) ; 49$ patients tested positive for hepatitis B surface antigen (HBsAg), whereas 391 tested negative. Finally, 3 cases (6.12\%) of HBVr due to imatinib for GIST were recorded. This study protocol was approved by the Medical Ethics Committee of Xiangya Hospital, Central South University (Changsha, Hunan, China).

\section{RESULTS}

\section{Case 1}

A 50-year-old woman with a history of HBV infection over 20 years presented with abdominal pain, hematemesis, hematochezia, and even syncope on December 29, 2018. The patient had no experience using antivirals for $\mathrm{HBV}$ or hepatotoxic drugs. She

\footnotetext{
Abbreviations: ALT, alanine transaminase; AST, aspartate transaminase; CT, computed tomography; GISTs, gastrointestinal stromal tumors; $\mathrm{HBcAg}$, hepatitis B core antigen; $\mathrm{HBeAb}$, hepatitis B e-antibody; $\mathrm{HBeAg}$, hepatitis B e-antigen; HBsAb, hepatitis B surface antibody; HBsAg, hepatitis B surface antigen; HPF, high-power field; $\mathrm{HBV}$, hepatitis B virus reactivation; NIH, National Institutes of Health; PDGFRA, platelet-derived growth receptor alpha.
}

was diagnosed with GIST by gastroscopy and abdominal-pelvic computed tomography (CT) scan. At the time of diagnosis, the patient had a normal liver function. Serologic tests for HBV showed that the patient was positive for HBsAg, hepatitis B e-antibody ( $\mathrm{HBeAb})$, hepatitis $\mathrm{B}$ core antigen ( $\mathrm{HBcAg}$ ) but negative for hepatitis B e-antigen ( $\mathrm{HBeAg}$ ) and hepatitis B surface antibody (HBsAb). The HBV DNA level was $3.10 \times 10^{4} \mathrm{IU} / \mathrm{mL}$ (normal, $<10$ $\mathrm{IU} / \mathrm{mL}$ ). The patient underwent resection of two tumors with partial resection of the stomach on January 11,2019. Postoperative pathology confirmed the diagnosis of two gastric GISTs [size, $10.5 \mathrm{~cm} \times 7 \mathrm{~cm} \times 6 \mathrm{~cm}$ and $4 \mathrm{~cm} \times 2.5 \mathrm{~cm} \times 2 \mathrm{~cm}$; mitosis, both $>5 / 50$ high-power field (HPF)]. Immunohistochemistry indicated that the tumors were positive for CD34, CD117, Dog1, and Ki-67 (3\%). Mutational analysis demonstrated a mutation in KIT exon 11. The patient was classified as high-risk under the modified National Institutes of Health (NIH) classification system (2008) (10). To reduce the risk of tumor recurrence, administration of imatinib $400 \mathrm{mg}$ daily was started postoperatively in January 2019.

On June 25, 2019, the patient presented with nausea, vomiting, and jaundice. Liver function tests showed elevated aspartate transaminase (AST) at 434.0 $\mathrm{U} / \mathrm{L}$ (normal, 13.0-35.0 $\mathrm{U} / \mathrm{L}$ ), alanine transaminase (ALT) at 407.0 U/L (normal, 7.0-40.0 $\mathrm{U} / \mathrm{L}$ ), total bilirubin at $24.5 \mathrm{umol} / \mathrm{L}$ (normal, $1.7-17.1 \mathrm{umol} / \mathrm{L}$ ), and direct bilirubin at $12.4 \mathrm{umol} / \mathrm{L}$ (normal, $0.0-6.8 \mathrm{umol} / \mathrm{L}$ ). No change in serum HBV serology was indicated, and the HBV DNA level increased to $3.57 \times 10^{6} \mathrm{IU} / \mathrm{mL}$. With the exclusion of other causes of liver injury such as infection with hepatitis A, C, or E virus, cytomegalovirus, Epstein-Barr virus, and autoimmune hepatitis, a diagnosis of imatinib-related chronic HBV reactivation was established. Thus, the patient immediately received entecavir $(0.5 \mathrm{mg} / \mathrm{d})$, discontinued imatinib, and took artificial extracorporeal liver support 3 times for severe liver damage. After 1 month, the symptoms and liver function abnormalities resolved. The HBV DNA level decreased to $6.59 \times 10^{2} \mathrm{IU} / \mathrm{mL}$. After discharge, the patient continued to take entecavir $(0.5 \mathrm{mg} / \mathrm{d})$ (up to present). In January 2020, the patient resumed taking low-dose imatinib $(100 \mathrm{mg} / \mathrm{d})$, with doses increased to $200 \mathrm{mg} / \mathrm{d}$ in February 2020 and $300 \mathrm{mg} / \mathrm{d}$ from March up to present. Patient recovery was uneventful. In April 2020, her liver function subsequently remained within normal ranges, No HBV DNA was detected, and no evidence of GIST recurrence was found in the abdominal-pelvic CT scan.

\section{Case 2}

A 59-year-old man without any symptoms was diagnosed with GIST by physical examination including gastroscopy in November 2018. He was diagnosed with HBV infection 20 years ago without undergoing antiviral therapy. After admission to the local hospital, he tested positive for HBsAg, $\mathrm{HBeAb}$, and $\mathrm{HBcAg}$ but negative for $\mathrm{HBs} A b, \mathrm{HBeAg}$, hepatitis $\mathrm{C}$ virus, and normal liver function. He underwent laparoscopic complete stomach resection of the tumor with an uncomplicated postoperative course. The mass was diagnosed as a gastric GIST and categorized as high-risk in accordance with the modified NIH classification system (2008) (10). (size, $7 \mathrm{~cm} \times 5 \mathrm{~cm} \times 4 \mathrm{~cm}$ mitosis, $>5 / 50 \mathrm{HPF}$ ). Immunohistochemistry showed the 
following: CD117(+), CD34(+), Dog-1(+), and Ki-67 (<8\%). Adjuvant treatment with imatinib $(400 \mathrm{mg} / \mathrm{d})$ was started on December 23, 2018.

In January 2019, the patient manifested abdominal pain. Laboratory and imaging tests showed normal results. The abdominal pain resolved after symptomatic treatment. In February 2019, the patient presented with edema of eyelids, hands, and ankles as side effects of imatinib. On May 15, 2019, the patient was admitted to a local hospital because of increasing systemic edema. Owing to serious side effects, imatinib administration was stopped. From November 2018 to May 2019, the patient received imatinib (400 mg/d), and his liver function was normal. No other hepatotoxic medication, except for imatinib, was taken.

However, after discontinuing imatinib, the patient reported dizziness, body weakness, and weight loss in June 2019. The patient was immediately admitted to Xiangya hospital. Laboratory findings showed the following measurements: ALT, 977.1 U/L (normal, 7.0-40.0 U/L); AST, 1382.0 U/L (normal, 13.0-35.0 U/L); total bilirubin, $20.5 \mathrm{umol} / \mathrm{L}$ (normal, 1.7-17.1 umol/L); and direct bilirubin, $11.3 \mathrm{umol} / \mathrm{L}$ (normal, 0.0-6.8 umol/L). Serology results indicated no change in serum $\mathrm{HBV}$; moreover, HBV DNA was $6.11 \times 10^{7} \mathrm{IU} / \mathrm{mL}$ (normal $<10 \mathrm{IU} /$ $\mathrm{mL}$ ), and the tumor marker CA125 was $82.73 \mathrm{U} / \mathrm{mL}$ (normal, 0$35.00 \mathrm{U} / \mathrm{mL}$ ). However, positron emission tomographycomputed tomography did not indicate recurrence or metastasis of GIST and other tumors. Thus, HBVr was identified as the potential cause of liver damage, and the patient was immediately administered entecavir $(0.5 \mathrm{mg} / \mathrm{d})$. However, the clinical condition of the patient progressively deteriorated because of severe hepatitis caused by HBVr. The patient ultimately developed severe liver failure leading to death.

\section{Case 3}

A 51-year-old man was found to have multiple hepatic masses and a gastric mass after a physical examination in September 2019. The patient subsequently underwent radical surgical resection for the gastric mass and palliative resection for the hepatic masses in a local hospital. The patient had a history of $\mathrm{HBV}$ infection of over 10 years but received no antiviral therapy for HBV. During hospitalization, the patient showed normal liver function, tested positive for $\mathrm{HBsAg}, \mathrm{HBeAb}$, and $\mathrm{HBcAb}$, and tested negative for $\mathrm{HBs} A \mathrm{~b}, \mathrm{HBcAb}$, and hepatitis $\mathrm{C}$ virus. Pathological examination revealed that the gastric mass was a high-risk gastric GIST (size, $4.5 \mathrm{~cm} \times 3.5 \mathrm{~cm} \times 3 \mathrm{~cm}$; mitotic index $>10 / 50 \mathrm{HPF}$ ), which stained positive for CD117, CD34, DOG1, and ki-67 (20\%). The liver mass was a metastatic GIST (the maximum tumor diameter was $1.5 \mathrm{~cm}$ ), which stained positive for DOG1; one lymph node was metastatic (1/1). Additional molecular analysis confirmed the mutation in KIT exon 11. The liver metastases were only partly removed, requiring lifetime treatment with imatinib $(400 \mathrm{mg} / \mathrm{d})$, which the patient started to receive in January 2020.

Regular laboratory examination after treatment with imatinib for 3 months showed that the patient had mildly elevated ALT, 80.0 U/L (normal, 9.0-50.0 U/L), but no symptoms and signs. Laboratory examination after treatment with imatinib for 6 months showed further increases in ALT to 282.6 U/L (normal, 9.0-50.0 U/L), AST to 154.0 U/L (normal, 15.0-40.0 U/L), total bilirubin to $19.9 \mathrm{umol} / \mathrm{L}$ (normal, 1.7-17.1 umol/L), and direct bilirubin to $10.5 \mathrm{umol} / \mathrm{L}$ (normal, 0.0-6.8 umol/L). HBV DNA was $4.99 \times 10^{8} \mathrm{IU} / \mathrm{ml}$ (normal, < $10 \mathrm{IU} / \mathrm{ml}$ ). Serology testing results showed that HBsAg and $\mathrm{HBcAb}$ were positive, whereas $\mathrm{HBsAb}$, $\mathrm{HBeAb}$, and $\mathrm{HBeAg}$ were negative. After excluding other causes of hepatitis, we considered that hepatitis could be attributable to HBVr. Thus, entecavir $(0.5 \mathrm{mg} / \mathrm{d})$ was administered, and imatinib was discontinued immediately. The patient now was followed up under close observation.

\section{LITERATURE REVIEW}

We performed a literature search in PubMed for other reported cases by using the terms "Hepatitis B virus reactivation", "Gastrointestinal stromal tumors," and "imatinib" and identified only 2 case reports $(8,9)$. The aforementioned cases, together with the 3 cases presented in the current study, complete the 5 cases currently reported (Table $\mathbf{1}$ ).

In the 5 cases, the average age of the patients was $61.8 \mathrm{y}$ (range: $50-87$ y), with a male-to-female ratio of $4: 1$. Four patients received imatinib as adjuvant treatment for intermediate- $(n=1)$ or highrisk $(n=3)$ recurrence based on the modified NIH classification system (2008) (10), and 1 patient received neoadjuvant treatment. Primary tumors were located in the stomach $(n=4)$ or rectum $(n=1)$, and one of our patients with a gastric GIST had liver metastasis. Imatinib at $400 \mathrm{mg}$ daily was started in accordance with consensus-based medication (10) in 4 patients and $200 \mathrm{mg}$ daily in 1 patient suffering from chronic kidney disease (stage $3 b$ ). Abnormal liver function was reported in 3 patients during the $6^{\text {th }}$ month of treatment with imatinib at $400 \mathrm{mg} / \mathrm{d}$ and in 1 patient during the $2^{\text {nd }}$ month of the same treatment at the same dose. Meanwhile 1 patient was diagnosed with $\mathrm{HBVr}$ during the $10^{\text {th }}$ month of treatment with 6 dose adjustments of imatinib, as follows: $200 \mathrm{mg} / \mathrm{d}$ for $10 \mathrm{~d}$, held for 2 weeks; $100 \mathrm{mg} / \mathrm{d}$ for 3 months; and 400 $\mathrm{mg} / \mathrm{d}$ for $40 \mathrm{~d}$, held for 2 weeks, and restarted at $200 \mathrm{mg} / \mathrm{d}$ imatinib. We observed the change in HBV DNA $\left(3.10 \times 10^{4} \mathrm{IU} / \mathrm{mL}\right.$ to $3.57 \times$ $10^{6} \mathrm{IU} / \mathrm{mL}$ ) before and after $\mathrm{HBVr}$ in 1 patient, which was attributed to treatment with imatinib, as well as the high level of HBV DNA following HBVr in 4 patients.

Treatment with imatinib was stopped in all patients following HBVr. Four patients received entecavir as antiviral treatment, and 1 patient received tenofovir. Two patients accepted liver transplant or artificial extracorporeal liver support to reverse the deterioration of their liver function. Three patients successfully recovered, 1 patient underwent treatment, and 1 patient died due to severe liver failure.

\section{DISCUSSION}

Imatinib has indeed changed the fate of patients with GIST and Philadelphia chromosome-positive chronic myeloid leukemia by targeting the oncogenic drivers of these diseases-BCR-ABL1 and 


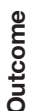

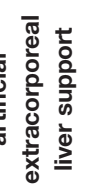

音
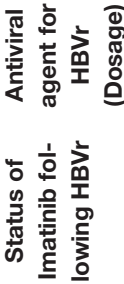

这离

兴京

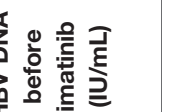

$\Omega$

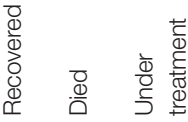

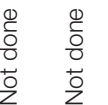

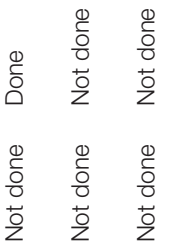

"ू.

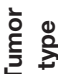

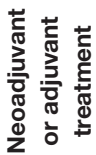

๕ัญ

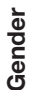

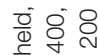

वृ.

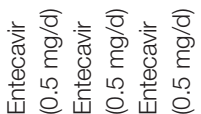

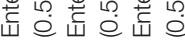

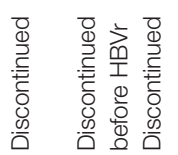

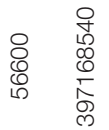

$\circ$ 우

$6 \sim$
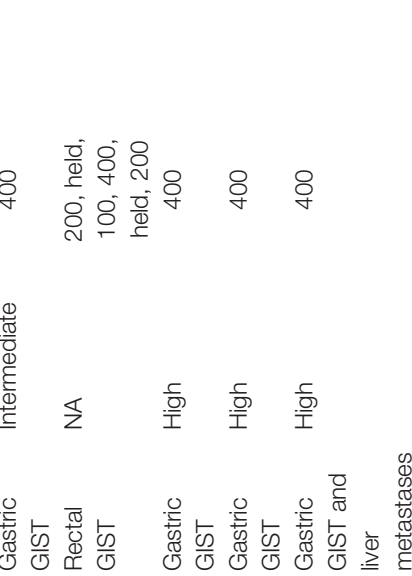

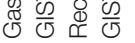

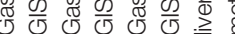
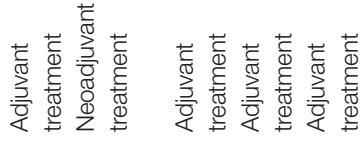

$\tilde{\sigma} \quad \hat{\infty}$

ட ถ

$\Sigma \Sigma$$$
\leftarrow \quad \Sigma \Sigma
$$

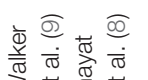

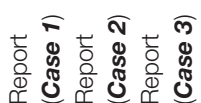

KIT and/or PDGFRA-mutations that promote the function of tyrosine kinase activities (11). The importance of imatinib, as the mainstay of treatment for GIST, has been emphasized in various clinical guidelines $(10,12,13)$. The side effects of imatinib are usually mild and generally well tolerated by most GIST patients (14). HBVr rarely occurs in patients infected with chronic HBV. However, when GIST patients with chronic HBV infection receive imatinib, the risk for $\mathrm{HBVr}$ is present. Without timely adequate recognition and treatment, $\mathrm{HBVr}$ can lead to an unfavorable prognosis or even death, such as that in Case 2, or increase the risk of tumor recurrence and progression, such as that in Case 3. GIST patients with chronic HBV infection and treated with imatinib rarely suffer from $\mathrm{HBVr}$; regardless, these cases need to be consolidated to raise awareness of complications.

\section{Definition of $\mathrm{HBVr}$}

No unified diagnostic criteria for HBVr have been established worldwide; however, a consensus has been reached for patients with $\mathrm{HBsAg}(+) / \mathrm{HBcAb}(-)$ or $\mathrm{HBsAg}(-) / \mathrm{HBcAb}(+)$ receiving immunosuppressive therapy or chemotherapy. HBVr is defined as the occurrence of any of the following: a hundredfold increase in the HBV DNA level, the recurrence of detectable HBV DNA or positive $\mathrm{HBsAg}$, or $\mathrm{HBV}$ DNA $>10^{5} \mathrm{IU} / \mathrm{mL}$ without a previously known HBV DNA level baseline $(7,15)$. Imatinib-induced hepatotoxicity has been reported and the incidence is less than $2.5 \%$ in patients with GIST (16); however, liver dysfunction usually resolves with either dose reduction or the discontinuation of the drug, which clearly contradicts Case 2 in the current study. Thus, the 3 cases presented meet the definition of HBVr. Notably, HBVr occurs not only in patients with overt chronic HBV infection but also in patients with resolved HBV infection (17).

$\mathrm{HBVr}$ is usually divided into two stages: (i) immediately after immunosuppressive therapy with the induction of $\mathrm{HBV}$ replication, reflecting a sharp increase in serum HBV DNA, and (ii) during withdrawal or a decrease in immune suppression. In stage (ii), patients tend to develop immune reconstitution that may lead to hepatocellular injury and even liver failure (18).

\section{Mechanism of Imatinib-Induced HBVr}

The mechanism by which imatinib induces HBVr has yet to be determined. However, a review of the relevant literature suggests that imatinib is directly and/or indirectly (by immunosuppressive function) involved in $\mathrm{HBVr}$ (Table 2). HBV covalently closed circular DNA and low levels of HBV DNA and RNA can be detected in host hepatocytes even in patients who have recovered from $\mathrm{HBV}$ and produced HBsAg after complete clearance of serum HBsAg and HBV DNA from a recent infection (26). When the immunity of the body, particularly the cellular immune function, is inhibited, viral replication increases, inducing an imbalance in the mechanisms that lead to HBVr (27). The imbalance between host immune response and $\mathrm{HBV}$ replication seem to indirectly cause HBVr. Although imatinib was not defined as an immunosuppressant, evidence has suggested that it exhibits an immunoregulatory effect. Imatinib at $400-800 \mathrm{mg} / \mathrm{d}$ inhibits the differentiation and function of dendritic cells (DCs), reducing the efficiency of priming cytotoxic T cell lymphocytes (CTLs) $(19,20)$. It also reduces memory B-cell frequencies and the secondary expansion 
TABLE 2 | Mechanism of Hepatitis B virus reactivation induced by imatinib.

\begin{tabular}{llc}
\hline $\begin{array}{l}\text { Reactivation } \\
\text { modes of } \\
\text { HBV }\end{array}$ & \multicolumn{1}{c}{ Activation mechanisms } & Reference \\
\hline $\begin{array}{l}\text { Indirect } \\
\text { reactivation of } \\
\text { HBV }\end{array}$ & $\begin{array}{l}\text { Inhibiting the differentiation and function of dendritic } \\
\text { cells }\end{array}$ & $(19,20)$ \\
& $\begin{array}{l}\text { Inhibiting memory cytotoxic T cell expansion } \\
\text { Reducing memory B-cell and impairing humoral }\end{array}$ & $(21)$ \\
& $\begin{array}{l}\text { immune responses } \\
\text { Reducing T-cell proliferation and activation }\end{array}$ & $(23,24)$ \\
reactivation of \\
HBV & $\begin{array}{l}\text { Inhibiting c-Abl kinase to downregulate CRL4 } \\
\text { activity, suppress CRL4 } \\
\text { of HBV } \text {-mediated ubiquitination }\end{array}$ & \\
& $\begin{array}{l}\text { reactivation } \\
\text { rect }\end{array}$ & \\
\hline
\end{tabular}

of memory CTLs, resulting in impaired protection against reinfection $(21,22)$. Moreover, several in vitro studies using T cells isolated from human peripheral blood have demonstrated a dose-dependent reduction in T-cell proliferation and activation in the presence of imatinib $(23,24)$. Imatinib also inhibits immunity to several disease, such as herpes zoster infection (28), tuberculosis (29), Epstein Barr Virus-positive lymphoproliferative disease (30), and sclerotic-type chronic graft-versus-host disease, in addition to HBVr (31). However, imatinib can stimulate anticancer responses mediated by T cells, interferon-producing killer DCs and NK cells in patients (11, 32-34). Thus, further research is needed to distinguish the difference in effect of imatinib between viral immunity regulation and tumor immunity regulation.

In addition to indirect reactivation by immunosuppression, imatinib can directly activate HBV. Moreover, c-Abl kinase promotes the $C R L 4^{C d t 2}$ mediated ubiquitination of $\mathrm{HBV}$ polymerase and further suppresses HBV replication. However, inhibiting c-Abl kinase activity with imatinib can lead to the accumulation of $\mathrm{HBV}$ polymerase protein and release of $\mathrm{HBV}$, and consequently to $\mathrm{HBVr}$ (25). Clinical HBV replication in patients with chronic HBV may be activated via direct and indirect pathways; however the exact mechanism of $\mathrm{HBVr}$ induced by imatinib is unknown and needs further study.

\section{Prevention and Treatment}

With the introduction of imatinib, GIST patients often have a good prognosis of long-term survival and quality of life. However, some patients develop HBVr, causing acute fatal liver failure and even death. According to the guideline (35), imatinib is associated with a moderate risk ( $1 \%$ to $10 \%$ incidence rate of $\mathrm{HBVr}$ ). Therefore, early prevention, diagnosis, and treatment of $\mathrm{HBVr}$ are extremely significant for GIST patients receiving imatinib therapy.

Prompt identification of $\mathrm{HBV}$-infected patients is mandatory before administering imatinib to prevent $\mathrm{HBVr}$ (36). HBV prophylaxis, identification of $\mathrm{HBV}$ patients, or reactivation monitoring can effectively prevent imatinib discontinuation. Conducting $\mathrm{HBsAg}$ and $\mathrm{HBcAb}$ tests is widely recommended before administering immunosuppressors $(37,38)$. If chronic $\mathrm{HBV}$ infection is evident, $\mathrm{HBsAb}, \mathrm{HBeAg}, \mathrm{HBeAb}$, and $\mathrm{HBV}$ DNA may be tested selectively for risk stratification (39). HBsAgpositive tumor patients are suggested to undergo antiviral therapy 1 week before receiving immunosuppressors or are given antivirals and imatinib simultaneously and continue to suppress the risk for $\mathrm{HBVr}$ during treatment. The reason is that $\mathrm{HBVr}$-induced hepatitis is more difficult to control and cure (37). Prophylactic therapy can potentially reduce the incidence of $\mathrm{HBVr}(40)$. ALT, AST and HBV DNA should be tested every 3 to 6 months during prophylaxis (6). Moreover, $\mathrm{HBcAb}$-positive and HBsAg-negative GIST patients should be monitored every 1-3 months for their ALT, HBV DNA and HBsAg levels during treatment $(6,41)$. If the tests turn positive under close surveillance, antiviral treatment is started immediately (42). In principle, both therapy for HBV patients with normal immunity function and therapy for HBVr patients should reach the same therapeutic endpoint (43). GIST patients receiving antivirals during treatment with imatinib need to continue their antivirals for 6-12 months after treatment with imatinib $(37,44)$.

When GIST patients experience HBVr, treatment with imatinib should be stopped, and antiviral treatment should be immediately initiated to avoid unfavorable outcomes. As soon as HBVr was evident, imatinib was instantly discontinued in 4 (except Case 2) of the 5 cases presented. Most patients had a good prognosis. Owing to its efficacy in reducing the occurrence of $\mathrm{HBVr}$, lamivudine is widely used in the treatment of cancer patients undergoin $g$ chemotherapy (45). However, long-term use of lamivudine may lead to HBV resistance mutations and drug resistance. Compared with lamivudine, some more recent drugs such as entecavir may reduce the risk of drug resistance $(46)$. Numerous studies $(47,48)$ have shown that entecavir can effectively inhibit viral replication and improve liver inflammation; moreover, it has an adequate safety index. Thus, entecavir is often considered as a first-line agent. Tenofovir disoproxil fumarate and tenofovir alafenamide fumarate also provide alternatives $(49,50)$.

One patient had artificial extracorporeal liver support and another patient had a liver transplant, and each had a good prognosis. Although some GIST patients with HBVr underwent antiviral and supportive treatment, their liver function still deteriorated. If liver injury could not be controlled by antivirals and liver-protective drugs, prompt artificial extracorporeal liver support as treatment choice would save the patient as in Case 1. For a favorable prognosis, a liver transplant is also a therapeutic choice (the case in Walker's study) for patients with tumors (such as GIST) and suffering acute liver failure.

However, our study has several limitations. First, a small number of cases was included in the review, and the follow-up period was short. Second, this study is a retrospective study with possible selection bias. Third, the management and monitoring of $\mathrm{HBVr}$ in patients with GIST were not based on research concerning GIST patients with HBVr induced by imatinib but were merely suggested as feasible by current clinical evidence. More prospective clinical random control trials are needed to improve clinical understanding of severe complications.

\section{CONCLUSION}

HBVr has a relatively low incidence rate $(6.12 \%)$. Regardless, the occurrence of HBVr in GIST patients undergoing treatment with 
imatinib cannot be ignored, particularly in China, which has a high rate of $\mathrm{HBV}$ infection. $\mathrm{HBVr}$ prophylaxis and monitoring seem effective and safe for the management of these patients. Thus, serology testing for HBsAg and HBcAb in GIST patients and prophylactic therapy for patients at high risk for HBVr needs to be conducted prior to the initiation of treatment with imatinib. Meanwhile, cessation of treatment with imatinib and initiation of antiviral therapy are mandatory following HBVr.

\section{DATA AVAILABILITY STATEMENT}

The original contributions presented in the study are included in the article/supplementary material. Further inquiries can be directed to the corresponding author.

\section{ETHICS STATEMENT}

The studies involving human participants were reviewed and approved by Xiangya Hospital of Central South University. The

\section{REFERENCES}

1. von Mehren M, Randall RL, Benjamin RS, Boles S, Bui MM, Ganjoo KN, et al. Soft Tissue Sarcoma, Version 2.2018, NCCN Clinical Practice Guidelines in Oncology. J Natl Compr Canc Netw (2018) 16(5):536-63. doi: 10.6004/ jnccn.2018.0025

2. Mantese G. Gastrointestinal stromal tumor: epidemiology, diagnosis, and treatment. Curr Opin Gastroenterol (2019) 35(6):555-9. doi: 10.1097/ MOG.0000000000000584

3. Joensuu H, Roberts PJ, Sarlomo-Rikala M, Andersson LC, Tervahartiala P, Tuveson D, et al. Effect of the tyrosine kinase inhibitor STI571 in a patient with a metastatic gastrointestinal stromal tumor. N Engl J Med (2001) 344 (14):1052-6. doi: 10.1056/NEJM200104053441404

4. Verweij J, Casali PG, Zalcberg J, LeCesne A, Reichardt P, Blay JY, et al. Progression-free survival in gastrointestinal stromal tumours with high-dose imatinib: randomised trial. Lancet (2004) 364(9440):1127-34. doi: 10.1016/ S0140-6736(04)17098-0

5. Chang SC, Liao CH, Wang SY, Tsai CY, Chiang KC, Cheng CT, et al. Feasibility and Timing of Cytoreduction Surgery in Advanced (Metastatic or Recurrent) Gastrointestinal Stromal Tumors During the Era of Imatinib. Med (Baltimore) (2015) 94(24):e1014. doi: 10.1097/MD.0000000000001014

6. European Association for the Study of the Liver. Electronic address eee, European Association for the Study of the L. EASL 2017 Clinical Practice Guidelines on the management of hepatitis B virus infection. J Hepatol (2017) 67(2):370-98. doi: 10.1016/j.jhep.2017.03.021

7. Chinese Society of Infectious Diseases CMA. Chinese Society of Hepatology CMA. [The guidelines of prevention and treatment for chronic hepatitis B (2019 version)]. Zhonghua Gan Zang Bing Za Zhi (2019) 27(12):938-61. doi: 10.3760/cma.j.issn.1007-3418.2019.12.007

8. Inayat F, Song F, Ali NS, Aslam MH, Aloma A, Hachem H, et al. Hepatitis B virus reactivation following imatinib therapy: A comparative review of 9 cases. J Oncol Pharm Pract (2019) 25(6):1500-8. doi: 10.1177/ 1078155218790337

9. Walker EJ, Simko JP, Ko AH. Hepatitis B viral reactivation secondary to imatinib treatment in a patient with gastrointestinal stromal tumor. Anticancer Res (2014) 34(7):3629-34.

10. Li J, Ye Y, Wang J, Zhang B, Qin S, Shi Y, et al. Chinese consensus guidelines for diagnosis and management of gastrointestinal stromal tumor. Chin J Cancer Res (2017) 29(4):281-93. doi: 10.21147/j.issn.1000-9604.2017.04.01 patients/participants provided their written informed consent to participate in this study. Written informed consent was obtained from the individual(s) for the publication of any potentially identifiable images or data included in this article.

\section{AUTHOR CONTRIBUTIONS}

TL was the lead investigator and contributed to writing the article. HL, FT, and ZH were the chief investigator and the senior author of the article. PL and XZ assisted with setting up the project and its promotion and helped with editing of the report. All authors contributed to the article and approved the submitted version.

\section{FUNDING}

This study was supported by the Hunan Provincial Clinical Medical Technology Innovation Guidance Project, China (2018SK52604).
11. Zitvogel L, Rusakiewicz S, Routy B, Ayyoub M, Kroemer G. Immunological off-target effects of imatinib. Nat Rev Clin Oncol (2016) 13(7):431-46. doi: 10.1038/nrclinonc.2016.41

12. Casali PG, Abecassis N, Bauer S, Biagini R, Bielack S, Bonvalot S, et al. Gastrointestinal stromal tumours: ESMO-EURACAN Clinical Practice Guidelines for diagnosis, treatment and follow-up. Ann Oncol (2018) 29: iv68-78. doi: 10.1093/annonc/mdy095

13. Landi B, Blay JY, Bonvalot S, Brasseur M, Coindre JM, Emile JF, et al. Gastrointestinal stromal tumours (GISTs): French Intergroup Clinical Practice Guidelines for diagnosis, treatments and follow-up (SNFGE, FFCD, GERCOR, UNICANCER, SFCD, SFED, SFRO). Dig Liver Dis (2019) 51 (9):1223-31. doi: 10.1016/j.dld.2019.07.006

14. Waller CF. Imatinib Mesylate. Recent Results Cancer Res (2018) 212:1-27. doi: 10.1007/978-3-319-91439-8_1

15. Choi J, Lim YS. Characteristics, Prevention, and Management of Hepatitis B Virus (HBV) Reactivation in HBV-Infected Patients Who Require Immunosuppressive Therapy. J Infect Dis (2017) 216(suppl_8):S778-S84. doi: 10.1093/infdis/jix178

16. Seidel C, Fenner M, Langer F, Bantel H, Ganser A, Grunwald V. Imatinibinduced liver cirrhosis in a patient with advanced gastrointestinal stroma tumor (GIST). BMC Cancer (2012) 12:186. doi: 10.1186/1471-2407-12-186

17. Masarone M, De Renzo A, La Mura V, Sasso FC, Romano M, Signoriello G, et al. Management of the $\mathrm{HBV}$ reactivation in isolated $\mathrm{HBcAb}$ positive patients affected with Non Hodgkin Lymphoma. BMC Gastroenterol (2014) 14:31. doi: 10.1186/1471-230X-14-31

18. Hoofnagle JH. Reactivation of hepatitis B. Hepatology (2009) 49(5 Suppl): S156-65. doi: 10.1002/hep.22945

19. Boissel N, Rousselot P, Raffoux E, Cayuela JM, Maarek O, Charron D, et al. Defective blood dendritic cells in chronic myeloid leukemia correlate with high plasmatic VEGF and are not normalized by imatinib mesylate. Leukemia (2004) 18(10):1656-61. doi: 10.1038/sj.leu.2403474

20. Appel S, Boehmler AM, Grunebach F, Muller MR, Rupf A, Weck MM, et al. Imatinib mesylate affects the development and function of dendritic cells generated from CD34+ peripheral blood progenitor cells. Blood (2004) 103 (2):538-44. doi: 10.1182/blood-2003-03-0975

21. Mumprecht S, Matter M, Pavelic V, Ochsenbein AF. Imatinib mesylate selectively impairs expansion of memory cytotoxic $\mathrm{T}$ cells without affecting the control of primary viral infections. Blood (2006) 108(10):3406-13. doi: 10.1182/blood-2006-04-018705 
22. de Lavallade H, Khoder A, Hart M, Sarvaria A, Sekine T, Alsuliman A, et al. Tyrosine kinase inhibitors impair B-cell immune responses in CML through off-target inhibition of kinases important for cell signaling. Blood (2013) 122 (2):227-38. doi: 10.1182/blood-2012-11-465039

23. Seggewiss R, Lore K, Greiner E, Magnusson MK, Price DA, Douek DC, et al. Imatinib inhibits $\mathrm{T}$-cell receptor-mediated T-cell proliferation and activation in a dose-dependent manner. Blood (2005) 105(6):2473-9. doi: 10.1182/ blood-2004-07-2527

24. Dietz AB, Souan L, Knutson GJ, Bulur PA, Litzow MR, Vuk-Pavlovic S. Imatinib mesylate inhibits $\mathrm{T}$-cell proliferation in vitro and delayed-type hypersensitivity in vivo. Blood (2004) 104(4):1094-9. doi: 10.1182/blood2003-12-4266

25. Hou L, Zhao J, Gao S, Ji T, Song T, Li Y, et al. Restriction of hepatitis B virus replication by $\mathrm{c}$-Abl-induced proteasomal degradation of the viral polymerase. Sci Adv (2019) 5(2):eaau7130. doi: 10.1126/sciadv.aau7130

26. Yang HC, Kao JH. Persistence of hepatitis B virus covalently closed circular DNA in hepatocytes: molecular mechanisms and clinical significance. Emerg Microbes Infect (2014) 3(9):e64. doi: 10.1038/emi.2014.64

27. Oh MJ, Lee HJ. A study of hepatitis B virus reactivation associated with rituximab therapy in real-world clinical practice: a single-center experience. Clin Mol Hepatol (2013) 19(1):51-9. doi: 10.3350/cmh.2013.19.1.51

28. Mattiuzzi GN, Cortes JE, Talpaz M, Reuben J, Rios MB, Shan J, et al. Development of Varicella-Zoster virus infection in patients with chronic myelogenous leukemia treated with imatinib mesylate. Clin Cancer Res (2003) 9(3):976-80.

29. Daniels JM, Vonk-Noordegraaf A, Janssen JJ, Postmus PE, van Altena R. Tuberculosis complicating imatinib treatment for chronic myeloid leukaemia. Eur Respir J (2009) 33(3):670-2. doi: 10.1183/09031936.00025408

30. Bekkenk MW, Vermeer MH, Meijer CJ, Jansen PM, Middeldorp JM, Stevens SJ, et al. EBV-positive cutaneous B-cell lymphoproliferative disease after imatinib mesylate. Blood (2003) 102(12):4243. doi: 10.1182/blood-2003-07-2436

31. Arai S, Pidala J, Pusic I, Chai X, Jaglowski S, Khera N, et al. A Randomized Phase II Crossover Study of Imatinib or Rituximab for Cutaneous Sclerosis after Hematopoietic Cell Transplantation. Clin Cancer Res (2016) 22(2):31927. doi: 10.1158/1078-0432.CCR-15-1443

32. Balachandran VP, Cavnar MJ, Zeng S, Bamboat ZM, Ocuin LM, Obaid H, et al. Imatinib potentiates antitumor $\mathrm{T}$ cell responses in gastrointestinal stromal tumor through the inhibition of Ido. Nat Med (2011) 17(9):1094100. doi: $10.1038 / \mathrm{nm} .2438$

33. Larmonier N, Janikashvili N, LaCasse CJ, Larmonier CB, Cantrell J, Situ E, et al. Imatinib mesylate inhibits $\mathrm{CD} 4+\mathrm{CD} 25+$ regulatory $\mathrm{T}$ cell activity and enhances active immunotherapy against BCR-ABL- tumors. J Immunol (2008) 181(10):6955-63. doi: 10.4049/jimmunol.181.10.6955

34. Smyth MJ. Imatinib mesylate-uncovering a fast track to adaptive immunity. $N$ Engl J Med (2006) 354(21):2282-4. doi: 10.1056/NEJMcibr061878

35. Perrillo RP, Gish R, Falck-Ytter YT. American Gastroenterological Association Institute technical review on prevention and treatment of hepatitis B virus reactivation during immunosuppressive drug therapy. Gastroenterology (2015) 148(1):221-44.e3. doi: 10.1053/j.gastro.2014.10.038

36. Kusumoto S, Tobinai K. Screening for and management of hepatitis B virus reactivation in patients treated with anti-B-cell therapy. Hematol Am Soc Hematol Educ Program (2014) 2014(1):576-83. doi: 10.1182/asheducation2014.1.576

37. Terrault NA, Lok ASF, McMahon BJ, Chang KM, Hwang JP, Jonas MM, et al. Update on Prevention, Diagnosis, and Treatment of Chronic Hepatitis B: AASLD 2018 Hepatitis B Guidance. Clin Liver Dis (Hoboken) (2018) 12 (1):33-4. doi: 10.1002/cld.728

38. Jang JW, Choi JY, Bae SH, Yoon SK, Chang UI, Kim CW, et al. A randomized controlled study of preemptive lamivudine in patients receiving transarterial chemo-lipiodolization. Hepatology (2006) 43(2):233-40. doi: 10.1002/ hep. 21024

39. Huang SC, Yang HC, Kao JH. Hepatitis B reactivation: diagnosis and management. Expert Rev Gastroenterol Hepatol (2020) 14(7):565-78. doi: 10.1080/17474124.2020.1774364

40. Liu CJ, Chen PJ, Chen DS, Kao JH. Hepatitis B virus reactivation in patients receiving cancer chemotherapy: natural history, pathogenesis, and management. Hepatol Int (2013) 7(2):316-26. doi: 10.1007/s12072-0119279-6

41. Law MF, Ho R, Cheung CK, Tam LH, Ma K, So KC, et al. Prevention and management of hepatitis $\mathrm{B}$ virus reactivation in patients with hematological malignancies treated with anticancer therapy. World J Gastroenterol (2016) 22 (28):6484-500. doi: 10.3748/wjg.v22.i28.6484

42. Liu WP, Xiao XB, Xue M, Wang GQ, Wang XP, Song YQ, et al. Prophylactic Use of Entecavir for Lymphoma Patients With Past Hepatitis B Virus Infection: A Randomized Controlled Trial. Clin Lymphoma Myeloma Leuk (2019) 19(2):103-8. doi: 10.1016/j.clml.2018.11.008

43. Sarri G, Westby M, Bermingham S, Hill-Cawthorne G, Thomas HGuideline Development G. Diagnosis and management of chronic hepatitis B in children, young people, and adults: summary of NICE guidance. BMJ (2013) 346:f3893. doi: 10.1136/bmj.f3893

44. Sarin SK, Kumar M, Lau GK, Abbas Z, Chan HL, Chen CJ, et al. Asian-Pacific clinical practice guidelines on the management of hepatitis B: a 2015 update. Hepatol Int (2016) 10(1):1-98. doi: 10.1007/s12072-015-9675-4

45. Loomba R, Rowley A, Wesley R, Liang TJ, Hoofnagle JH, Pucino F, et al. Systematic review: the effect of preventive lamivudine on hepatitis $\mathrm{B}$ reactivation during chemotherapy. Ann Intern Med (2008) 148(7):519-28. doi: 10.7326/0003-4819-148-7-200804010-00008

46. Tang LSY, Covert E, Wilson E, Kottilil S. Chronic Hepatitis B Infection: A Review. JAMA (2018) 319(17):1802-13. doi: 10.1001/jama.2018.3795

47. Chang TT, Gish RG, de Man R, Gadano A, Sollano J, Chao YC, et al. A comparison of entecavir and lamivudine for $\mathrm{HBeAg}$-positive chronic hepatitis B. N Engl J Med (2006) 354(10):1001-10. doi: 10.1056/NEJMoa051285

48. Chang TT, Lai CL, Kew Yoon S, Lee SS, Coelho HS, Carrilho FJ, et al. Entecavir treatment for up to 5 years in patients with hepatitis B e antigenpositive chronic hepatitis B. Hepatology (2010) 51(2):422-30. doi: 10.1002/ hep. 23327

49. Gentile G, Andreoni M, Antonelli G, Sarmati L. Screening, monitoring, prevention, prophylaxis and therapy for hepatitis $B$ virus reactivation in patients with haematologic malignancies and patients who underwent haematologic stem cell transplantation: a systematic review. Clin Microbiol Infect (2017) 23(12):916-23. doi: 10.1016/j.cmi.2017.06.024

50. Sarmati L, Andreoni M, Antonelli G, Arcese W, Bruno R, Coppola N, et al. Recommendations for screening, monitoring, prevention, prophylaxis and therapy of hepatitis $\mathrm{B}$ virus reactivation in patients with haematologic malignancies and patients who underwent haematologic stem cell transplantation-a position paper. Clin Microbiol Infect (2017) 23(12):93540. doi: $10.1016 /$ j.cmi.2017.06.023

Conflict of Interest: The authors declare that the research was conducted in the absence of any commercial or financial relationships that could be construed as a potential conflict of interest.

Copyright (c) 2021 Lei, Tan, Hou, Liu, Zhao and Liu. This is an open-access article distributed under the terms of the Creative Commons Attribution License (CC BY). The use, distribution or reproduction in other forums is permitted, provided the original author(s) and the copyright owner(s) are credited and that the original publication in this journal is cited, in accordance with accepted academic practice. No use, distribution or reproduction is permitted which does not comply with these terms. 